\title{
Inhalt
}

Vorwort - V

Hélène Vinckel-Roisin

Facetten des Nachfelds im Deutschen - 1

\section{Strukturell-syntaktische Eigenschaften}

Gisela Zifonun

Der rechte Rand in der IDS-Grammatik: Evidenzen und Probleme - 25

Werner Frey

Zur Struktur des Nachfelds im Deutschen - 53

Maria Balbach

Das Nachfeld und das Adjektiv

Eine Untersuchung der Präpositionalobjekte des prädikativen Adjektivs im Deutschen - 77

André Meinunger

Vokative und resumptive Namensausdrücke im Nachfeld

Ansatz zu einer Erklärung für die Artikelpräsenz bei Personennamen unter Rechtsversetzung - $\mathbf{9 7}$

Angelika Wöllstein

Nachgestellte reine Infinitive - ein blinder Fleck - 117

\section{Sprachhistorische Perspektive}

Marco Coniglio und Eva Schlachter

Das Nachfeld im Deutschen zwischen Syntax, Informations- und

Diskursstruktur

Eine diachrone, korpusbasierte Untersuchung - 141

Said Sahel

Zur Ausklammerung von Relativsätzen und Vergleichsphrasen im frühen Neuhochdeutschen (1650-1800) -165 


\section{Pragmatisch-stilistische Funktionen}

Gottfried R. Marschall

Die poetisch-stilistische Besetzung des Nachfelds — 187

Mikaela Petkova-Kessanlis

Nachfeldbesetzungen und ihre kommunikative Funktion in wissenschaftlichen Texten -211

\section{Gesprochene Sprache}

Wolfgang Imo

Nachträge im Spannungsfeld von Medialität, Situation und interaktionaler Funktion -231

Susanne Günthner und Katharina König Temporalität und Dialogizität als interaktive Faktoren der Nachfeldpositionierung - ,irgendwie‘ im gesprochenen Deutsch — 255

Nadine Proske

Die Rolle komplexer Nachfeldbesetzungen bei der Einheitenbildung im gesprochenen Deutsch 279

Anja Kleemann-Krämer, Frank Kügler und Sarah Pötzl

Zur Anbindung extraponierter PPn an ihre Bezugsstruktur 299

Maria Alm

ALso als finale Partikel im Deutschen — 319

\section{Spracherwerb}

Daniela Elsner

Das Nachfeld in der Kindersprache

Möglichkeiten und Grenzen einer konstruktionsgrammatischen Analyse - 345 


\section{Eva Breindl}

Die Besetzung des Nachfelds bei fortgeschrittenen Lernern des Deutschen als Fremdsprache

Eine korpusbasierte Studie $-\mathbf{3 6 3}$

Sachregister -385 
